Article

\title{
Revisiting the Granger Causality Relationship between Energy Consumption and Economic Growth in China: A Multi-Timescale Decomposition Approach
}

\author{
Lei Jiang ${ }^{1, *}$ and Ling Bai ${ }^{2}$ \\ 1 School of Economics, Zhejiang University of Finance and Economics, Hangzhou 310018, China \\ 2 School of Economics and Management, Nanchang University, Nanchang 330031, China; \\ bling1987yy@163.com \\ * Correspondence: lei_jiang@zufe.edu.cn; Tel.: +86-138-6742-3820
}

Received: 13 November 2017; Accepted: 9 December 2017; Published: 11 December 2017

\begin{abstract}
The past four decades have witnessed rapid growth in the rate of energy consumption in China. A great deal of energy consumption has led to two major issues. One is energy shortages and the other is environmental pollution caused by fossil fuel combustion. Since energy saving plays a substantial role in addressing both issues, it is of vital importance to study the intrinsic characteristics of energy consumption and its relationship with economic growth. The topic of the nexus between energy consumption and economic growth has been hotly debated for years. However, conflicting conclusions have been drawn. In this paper, we provide a novel insight into the characteristics of the growth rate of energy consumption in China from a multi-timescale perspective by means of adaptive time-frequency data analysis; namely, the ensemble empirical mode decomposition method, which is suitable for the analysis of non-linear time series. Decomposition led to four intrinsic mode function (IMF) components and a trend component with different periods. Then, we repeated the same procedure for the growth rate of China's GDP and obtained four similar IMF components and a trend component. In the second stage, we performed the Granger causality test. The results demonstrated that, in the short run, there was a bidirectional causality relationship between economic growth and energy consumption, and in the long run a unidirectional relationship running from economic growth to energy consumption.
\end{abstract}

Keywords: energy consumption; ensemble empirical mode decomposition; Granger causality test; China

\section{Introduction}

The last four decades have witnessed rapid economic growth in China. In 2013, China became the second largest economy globally after the U.S. all over the world. China's economic success has been heavily dependent on a great deal of energy consumption. Notably in the past decade, its energy use surged at an unprecedented rate. According to statistics from the International Energy Agency, China took over the No. 1 position from the U.S. in terms of primary energy consumption in 2009 [1]. In 2015, China accounted for $22.9 \%$ of total primary energy consumption in the world [2].

A substantial amount of energy consumption has confronted China with two huge challenges: energy deficiency and environmental deterioration caused by fossil fuel combustion [3]. In view of the first challenge, there has been a huge energy shortage, notably of oil, for two decades. Since China is extremely short of oil reserves, it has long been dependent on imports. The dependence degree has risen to $50 \%$ at present. To sum up, the huge energy gap between energy production and energy consumption not only causes serious energy security issue, but also places significant pressures on the international energy market [4]. Regarding the second challenge, coal dominates the primary 
energy consumption structure, accounting for more than $65 \%$ of this, since China is abundant in coal resources reserves. Various kinds of pollutant emissions caused by coal combustion have worsened the environment for years. It is calculated that economic losses caused by environmental pollution amounts to $2-3 \%$ of China's GDP [5].

China's energy issues have been intensively debated in academic circles for years. A large number of studies pertaining to energy consumption and its determinants have been published over years from different perspectives. For example, Crompton and $\mathrm{Wu}[6]$ employed the Bayesian vector auto-regressive model (VAR) to predict energy consumption in China. Their results showed that energy consumption went up at the growth rate of 3.8\%. Liu [7] investigated the nexus between China's rapid urbanization process and energy consumption. He found that there exists a long-run relationship. Moreover, urbanization was a Granger causality for energy consumption not only in the short run, but also in the long run, however, not vice versa. Cattaneo et al. [8] took into account spatial spillovers and used a spatial econometric model to estimate Chinese demand for coal. Song et al. [5] figured out that changes in energy consumption were attributed to technological progress. Jiang and Lin [9] focused on energy demand in China's industrialization and urbanization processes. They concluded that energy demand in China would, in the midterm, maintain high growth. Fu et al. [10] placed an emphasis on China's domestic fixed investment-driven energy consumption. They built an energy input-output model to investigate the amount of energy consumption driven by domestic investment. Their results showed that China's rapid industrialization and urbanization processes mainly contributed to the large amount of energy consumption. In order to clarify the dilemma between a decline in exports in the financial crisis and the increase in energy consumption, Li et al. [11] employed a decomposition method to distinguish and explain the impact of domestic final use and international trade on China's energy consumption. Their results indicated that economic stimulus plans played the more important role in China's energy consumption growth in spite of the negative impact of the decline in international trade caused by the crisis on energy consumption. Lin and Ouyang [12] employed the panel co-integration technique to investigate influencing factors of China's energy consumption. An inverted U-shaped curve between energy consumption per capita and economic growth was found. Based on an energy decomposition method, Wang [13] decomposed the time series of energy consumption from 1980 to 2011 in China into four specific effects, namely, the technological progress effect, the industrial structure effect, the economic growth effect, and the energy supply's structural effect. Similarly, Zhang and Lahr [4] applied the structural decomposition analysis (SDA) method in order to disclose regional heterogeneity in energy consumption from 1987 to 2007 after classifying Chinese provinces into seven regions. They decomposed energy consumption changes into six partial effects.

The empirical studies mentioned above have employed or have developed various approaches to analyzing China's energy consumption from different points of view. However, an investigation of how the characteristics of China's energy consumption changes from the perspective of multi-timescale has received little attention so far. In particular, existing studies focus more on the amount of Chinese energy consumption, but less on the growth rate of energy consumption. The underlying characteristics of the growth rate of China's energy consumption is needed for an explanation. Specifically, irregular shocks or events on different timescales may have different impacts on fluctuations of the growth rate. A question arises as to how to extract meaningful information on different timescales and identify the trend from these fluctuations. Hence, Huang et al. [14] has developed the empirical mode decomposition (EMD) method that is an adaptive time-series data analysis method. It is capable of extracting signals from data that are generated in non-linear processes. Subsequently, the EMD and improved EMD method have been widely used in empirical studies in recent years, notably pertaining to energy issues. For example, Yu et al. [15] used the EMD method to analyze Brent crude oil spot prices and West Texas Intermediate crude oil spot prices. In a similar vein, Zhang et al. [16] paid attention to the impact of extreme events on crude oil markets. They decomposed crude oil prices and notably found fluctuations caused by two extreme events. Moreover, Xiong et al. [17], Yu et al. [18], 
Yu et al. [19], and Zhang et al. [20] also investigated crude oil prices by means of the EMD method. Moreover, this method has also been used to study electricity demand or prices [21-23].

To the best of our knowledge, research pertaining to the growth rate of energy consumption in China has received little attention in international literature. China, the biggest energy consumer globally, plays a significant role in the international energy market. Hence, a better understanding of the underlying characteristics of China's energy consumption not only helps policymakers implement effective measures to reduce energy use and pollutant emissions caused by fossil fuel combustion in an attempt to improve environmental quality, but also contributes to predicting the trend of demand for energy in the future. In this study, we attempt to apply the ensemble empirical mode decomposition (EEMD) method to investigate the intrinsic characteristics of the growth rate of China's energy consumption and extract fluctuations with periods on multi-timescales and a non-linear overall trend.

Another stream pertaining to the energy issue in academic circles has been to analyze the nexus between energy consumption and the economy, specifically, their causality relationships, by means of the Granger causality test. A growing number of studies pertaining to the nexus of economic growth and energy consumption in China have been published recently. For example, Zhang and Cheng [24] tested the causality relationship based on time-series data from 1960 to 2007. They found a unidirectional Granger causality running from economic growth to energy consumption. Similarly, Wang et al. [25] also used a multivariate regression model to examine the causality relationship for the period from 1972 to 2006 . They found short-run and long-run causality relationships running from energy consumption to economic growth. Nevertheless, these time-series studies may suffer from the shortcoming of insufficient sample size. To address this problem, a few researchers have adopted panel data to revisit these causality relationships in China. For example, Zhang and Xu [26] employed panel data models for the period of 1995 to 2008 to test the causality relationship. The results indicated that there existed a bidirectional causality relationship between economic growth and energy consumption in China. Furthermore, Herrerias et al. [27] provided a new insight into the relationship by taking into account regional dependence across the Chinese provinces, and disaggregating total energy consumption into coal, coke, crude oil and electricity consumption. Empirical evidence found a long-run unidirectional causality relationship running from economic growth to energy consumption. Besides, a large body of empirical studies pertaining to the relationships between economic growth and energy consumption in other countries and regions have been published over the past decades [28-31].

The empirical studies mentioned above used various techniques to examine the causality relationship. However, they drew different, even conflicting, conclusions. This is because these methods may suffer from two weaknesses. One is that they adopt the amount of energy consumption rather than the growth rate when using time-series data. The growth rate time series may better reflect intrinsic fluctuations and help to better understand how energy consumption changes. The other weakness is that they ignored the analysis of the causality relationship from a multi-timescale perspective. For example, in the Herrerias et al. [27] study, the VAR model and the error correction model were employed to test the short-run and long-run Granger causality relationships, respectively. Unlike their methods, in this research we attempt to decompose a time-series data into a trend component to denote the long-run trend of the time series. Subsequently, the decomposed trend component can be adopted to investigate the long-run causality relationship. To sum up, this study has two parts. One is to decompose the time series of growth rates of energy consumption and economic growth based on the EEMD method. The other is to estimate the short-run and long-run causality relationships between two decomposed time series obtained from the first stage by using the Granger causality test.

Furthermore, regarding the energy-GDP causality test, the literature has featured two different model specifications from the perspectives of the production function and the demand function. On the one hand, energy as an input factor like capital and labor can produce economic output, since neo-classical economic theory provides guidance on the causality relationship a priori. Hence, 
in the production framework, the more energy that is consumed, the greater the economic output and vice versa. Hence, a production function model, like the Cobb-Douglas production function, was constructed to test for the causality relationship [32,33]. On the other hand, economic development also causes consumption goods like energy consumption. Hence, a demand model including energy price was used to test for causality relationship since an energy price can signal the scarcity of an energy source [34,35]. Similarly, a bidirectional causality relationship would be expected since higher economic levels cause more energy consumed and vice versa. Many researchers are more interested in the demand causality model. However, the biggest challenge is a lack of energy price data. Alternatively, for Chinese studies, indices of raw materials, fuel and power are usually used to indicate the variable of energy prices. However, the data has been recorded only since the year 1990. In other words, the data is insufficient for this study. Most importantly, energy prices are tightly controlled in China so these cannot signal the scarcity of energy sources in China's market economy. Hence, in this study we follow Liddle and Lung [36] to employ a reduced form in order to examine the Granger causality relationship.

This study has three merits. The first is that we focus on the growth rate of energy consumption instead of the amount of energy consumption, since this conceals much useful information, for example, intrinsic fluctuations. The second is that we can obtain the long-run trend of the growth rate of both energy consumption and economic growth by means of the EEMD method. The last is that we provide a novel insight into the short-run and long-run Granger causality relationships between the two variables by performing the multi-timescale Granger causality tests, unlike the traditional VAR models and error correction models (ECM). To sum up, this study may help to better understand the causality relationship from a multi-timescale point of view.

The structure of this paper is arranged as follows. Section 2 presents methods used in this research and data sources; Section 3 exhibits empirical results and analyses; while Section 4 draws conclusions and proposes a series of implications.

\section{Method and Data Sources}

In this section, we first introduce the EEMD method in detail. It is employed to decompose the growth rate of energy consumption into several intrinsic mode function (IMF) components. Then, unit root tests are presented to test if each time series is stationary, followed by the Granger causality test to examine the causality relationships.

\subsection{EEMD Method}

The EEMD method is characterized by noise-assisted data analysis (NADA) that derives from the EMD method that was first proposed by Huang et al. [13,37]. Recently, it has extensively been used in a broad range of applications to analyze non-linear and non-stationary signals (or time series), notably in the field of natural sciences, for example, meteorology [38,39].

\subsubsection{EMD Method}

Before the introduction to the EEMD method, the EMD method is presented step by step in order to better understand the EEMD method. For one original signal $X(t)$, the first step is to identify all the local maxima and minima. Subsequently, we apply the cubic spline interpolation technique to obtain the upper envelope $u_{1}(\mathrm{t})$ and the lower envelope $u_{2}(\mathrm{t})$, respectively. Then, the local mean envelope $m_{1}(\mathrm{t})$ can be presented below:

$$
m_{1}(\mathrm{t})=1 / 2\left(u_{1}(\mathrm{t})+u_{2}(\mathrm{t})\right)
$$

Next, the first component $h_{1}(\mathrm{t})$ can be obtained by subtracting the local mean envelope $m_{1}(\mathrm{t})$ from the original data $X(t)$. It can be expressed as below:

$$
h_{1}(\mathrm{t})=X(\mathrm{t})-m_{1}(\mathrm{t})
$$


If $h_{1}(\mathrm{t})$ is the first IMF component, it must satisfy two conditions. One condition is that the number of extrema and zero crossings must be equal or differ at most by one. The other is that the mean value of the envelope must be zero at any point. Otherwise, if $h_{1}(\mathrm{t})$ does not satisfy the two aforementioned conditions, $h_{1}(\mathrm{t})$ is taken as the new $X(\mathrm{t})$. We repeat Equations (1) and (2) $k$ times until $h_{1 k}(\mathrm{t})$ satisfies the two conditions as the first IMF component. $h_{1 k}(\mathrm{t})$ can be described as follows.

$$
h_{1 k}(\mathrm{t})=h_{1(k-1)}(\mathrm{t})-m_{1 k}(\mathrm{t})
$$

In addition, $h_{1 k}(\mathrm{t})$ is an IMF component that depends on a stoppage criterion. The criterion is given as follows:

$$
S D=\sum_{\mathrm{t}=0}^{T}\left(\frac{h_{1(k-1)}(\mathrm{t})-h_{1 k}(\mathrm{t})}{h_{1(k-1)}(\mathrm{t})}\right)^{2}
$$

where $S D$ denotes standard deviation that is a pre-specified value. If $S D$ is set with a very small value, the above processes will be repeated too many times. Consequently, the IMF component will become a pure frequency modulation signal that possibly leads to losing its actual meaning. Empirically, a better $S D$ value ranges from 0.2 to 0.3 [39]. When $h_{1 k}(\mathrm{t})$ satisfies the pre-determined $S D$ value, it is called the first IMF component, or IMF1. We designate $h_{1 k}(\mathrm{t})$ as $C_{1}$.

When the first IMF component has been found, we can obtain residua $r_{1}(\mathrm{t})$ by subtracting $C_{1}$ from the original data $X(t)$. Its expression can be given as below:

$$
r_{1}(\mathrm{t})=X(\mathrm{t})-C_{1}
$$

Similarly, a series of $C_{2}, C_{3}, \ldots, C_{n}$, namely, IMF2, IMF3, $\ldots$, IMFn can be obtained by regarding $r_{1}(\mathrm{t})$ as a new data series and repeating the aforementioned procedure (from steps 1 to 5 ) stepwise.

The decomposition process will stop and no more IMF components can be obtained only when the residua $r_{n}(\mathrm{t})$ satisfies two conditions. One is that it becomes a monotonic function. The other is that it is a function having only one extremum. Hence, the residua $r_{n}(\mathrm{t})$ is usually considered as the trend.

The original signal data can be restructured by summing all components. It is given below:

$$
X(\mathrm{t})=\sum_{i=1}^{n}\left(C_{i}(\mathrm{t})+r_{n}(\mathrm{t})\right)
$$

In addition, the maximum number of IMF components is equal to $\log _{2} N$, where $N$ is the length of the original signal.

\subsubsection{EEMD Method}

The EMD method not only has a number of merits, but also suffers from a few weaknesses. One major weakness is mode mixing. Mode mixing refers to aliasing in the time-frequency distribution that results in the physical meaning of an individual IMF component being unclear. To address this shortcoming, the EEMD method first proposed by Wu and Huang [40] has been developed to deal with the potential problem in the non-linear and non-stationary signal data.

EEMD is a newly-developed and EMD-based method. Its principle is simple and clear. As mentioned above, the EEMD is a NADA method. Specifically, before the decomposition process, a white noise series is added to the original signal data. The algorithm of the EEMD is briefly described step by step. Step (1) is to add a white noise series to the original signal. Step (2) is to decompose the signal with added white noise obtained from step (1) into IMF components by means of the EMD method. Step (3) is to repeat steps (1) and (2) with different added white noise series each time. Step (4) 
is to obtain IMF components and then to adopt the mean values of the ensemble corresponding IMF components as the final results. This can be expressed as below:

$$
C_{j}(\mathrm{t})=\frac{1}{N} \sum_{i=1}^{N} C_{i j}(\mathrm{t})
$$

where $C_{j}(\mathrm{t})$ denotes the $j$ th final IMF component while $C_{i j}(\mathrm{t})$ is the $j$ th IMF component from the added white-noise trial. Moreover, $N$ is the number of white noise series.

The residua of the decomposition process will be a monotonic function that intrinsically describes the overall trend of the original signal [41,42]. Hence, we can restructure the original signal $X(t)$ by summing all IMF components. This is expressed below:

$$
X(\mathrm{t})=\mathrm{IMF} 1+\mathrm{IMF} 2+\ldots+\mathrm{IMFn}+\mathrm{RES}(\text { Trend })
$$

where RES denotes the residua. Its meaning refers to the long-run trend of the time-series variable. Specifically, after decomposition the RES of the growth rate of energy consumption implies the long-run trend of the growth rate. In other words, it can explicitly disclose whether the growth rate goes up or down in the long run.

In this research, we decompose two time-series data, namely China's energy consumption and economic growth (GDP) rates respectively from 1954 to 2015, into four IMF components and an overall trend by using the EEMD method. The frequencies of the four IMF components are settled in descending order, namely, from high frequency to low frequency [13,37].

\subsection{Unit Root Test}

Before testing for the Granger causality relationships between GDP and energy consumption, the first step is to test if all of the time-series variables are stationary or integrated of the same order. Hence, a unit root test is needed to test if each IMF component of growth rates of energy consumption and GDP is stationary.

We employ the augmented Dickey-Fuller (ADF) unit root test proposed by Dickey and Fuller $[43,44]$, which is widely applied in empirical studies. The null hypothesis is that "the time series is a non-stationary time series". If the null hypothesis is rejected, the time series is stationary, or taken to be integrated of order zero (I(0) for short). On the contrary, if the null hypothesis cannot be rejected, and the first difference of the time series is stationary, then it is integrated of of I(1).

The ADF test has three types of assumptions, specifically: no intercept and no trend (Equation (9)), intercept (Equation (10)), and intercept and trend (Equation (11)).

$$
\Delta y_{\mathrm{t}}=\theta y_{\mathrm{t}-1}+\sum_{i=1}^{p} \lambda_{i} \Delta y_{\mathrm{t}-i}+\mu_{i}
$$

where $y_{\mathrm{t}}$ is the series in time $\mathrm{t} ; \Delta$ implies the first difference; $\mu$ is the error term with a mean 0 and a variance $\sigma^{2}$.

$$
\Delta y_{\mathrm{t}}=\alpha+\theta y_{\mathrm{t}-1}+\sum_{i=1}^{p} \lambda_{i} \Delta y_{\mathrm{t}-i}+\mu_{i}
$$

where $\alpha$ denotes the intercept term.

$$
\Delta y_{\mathrm{t}}=\alpha+\beta \mathrm{t}+\theta y_{\mathrm{t}-1}+\sum_{i=1}^{p} \lambda_{i} \Delta y_{\mathrm{t}-i}+\mu_{i}
$$

where $\beta$ denotes the time trend. Moreover, the null hypothesis of the ADF test is $H_{0}: \theta=0$, and the alternative hypothesis is $H_{1}: \theta<0$. 


\subsection{Granger Causality Test}

The Granger causality test, first proposed by Granger [45], is commonly used to examine causality relationship between two time series variables. It is a statistical hypothesis test in order to determine if one variable affects the other. Technically speaking, $x$ and $y$ are two time-series variables. If " $x$ causes $y^{\prime \prime}$ by means of a set of statistics, it indicates that the current $y$ can be explained by past values of $x$ and that adding lagged values of $x$ to the model can enhance the explanation. When it comes to the nexus between energy consumption and economic growth, energy consumption may be affected not only by past energy consumption, but also by economic growth, and vice versa. The Granger causality test model reads as follows:

$$
\begin{aligned}
& y_{t}=\alpha_{0}+\sum_{j=1}^{p} \alpha_{j} y_{\mathrm{t}-j}+\sum_{j=1}^{p} \beta_{j} x_{\mathrm{t}-j}+\varepsilon_{\mathrm{t}} \\
& x_{\mathrm{t}}=\alpha_{0}+\sum_{j=1}^{p} \alpha_{j} x_{\mathrm{t}-j}+\sum_{j=1}^{p} \beta_{j} y_{\mathrm{t}-j}+\varepsilon_{\mathrm{t}}
\end{aligned}
$$

The null hypothesis in the first regression is that " $x$ does not Granger cause $y$ ". Similarly, the null hypothesis in the second equation is that " $y$ does not Granger cause $x$ ".

Technically speaking, the null joint hypothesis is given below.

$$
H_{0}: \beta_{1}=\beta_{2}=\cdots=\beta_{p}=0
$$

On the other hand, the alternative hypothesis is that at least one estimated parameter is not zero. It can be given as follows:

$$
H_{1}: \text { At least one } \beta_{j} \neq 0
$$

To better display how the research processes are conducted, the procedure of the analysis is shown in Figure 1.

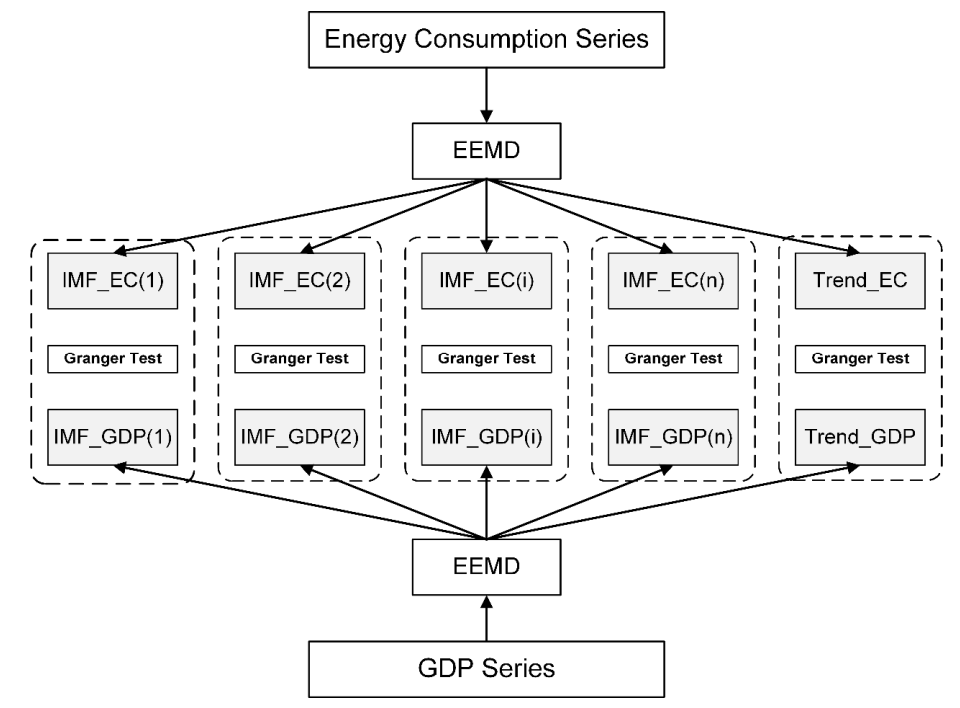

Figure 1. The framework of multi-scale time decomposition and the Granger causality test.

\subsection{Data}

Data for energy consumption and GDP are available from the China Statistical Yearbook 2016 (available at: http://www.stats.gov.cn/tjsj/ndsj/2016/indexch.htm). The annual growth rate of energy consumption is defined as "Rate $=\left(E n g_{t}-E n g_{t-1}\right) / E n g_{t} \times 100 \%$ ". The subscript $t$ refers to year $\mathrm{t}$ and $\mathrm{t}-1$ refers to one year lag. Eng denotes the amount of energy consumption. Similarly, so does the growth rate of GDP. 
Figure 2 shows the yearly energy consumption in China from 1953 to 2015. The trend of energy consumption may be broken into two parts with an interruption that occurred in 2002. In other words, the former part is from 1954 to 2001 and the latter from 2002 to 2014. In the first part, it grows gradually and constantly, while in the latter part, it surges at an exponential rate.

Furthermore, Figure 2 masks useful information on the dynamic or periodic characteristics of the increase in energy consumption, for example, differences in the growth rate on different timescales, and fluctuation patterns, etc. Notably, the growth rate fluctuates over time, presenting a non-linear process. It is plotted in Figure 3.

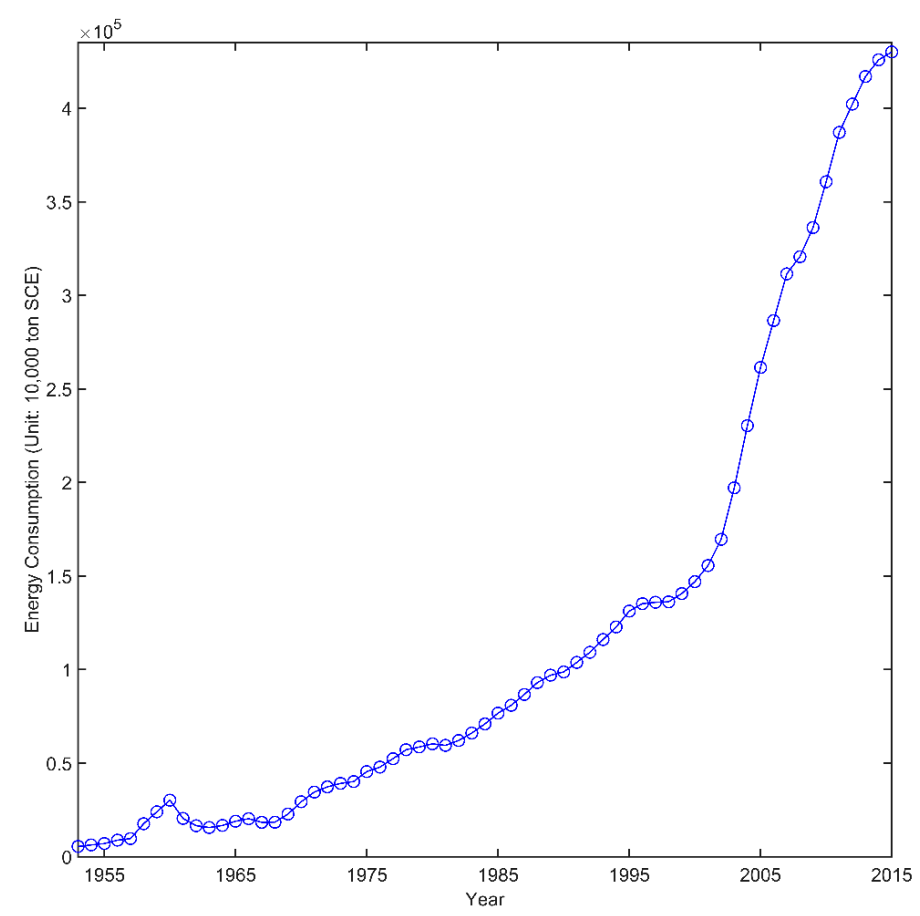

Figure 2. China's energy consumption from 1953 to 2015.

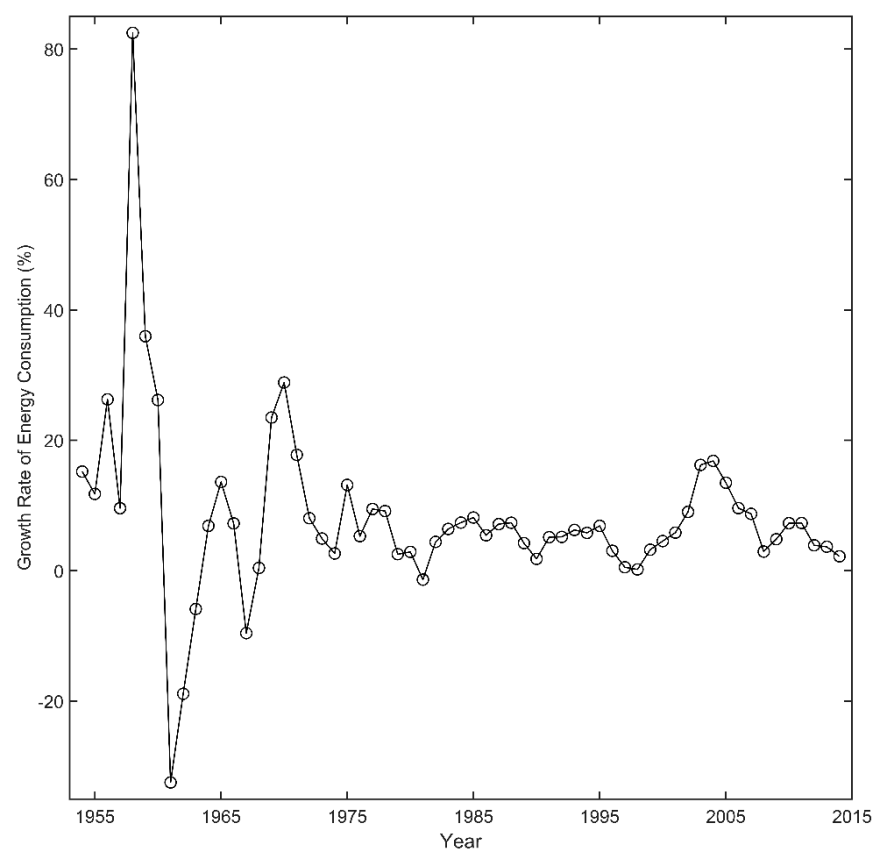

Figure 3. Yearly growth rate of energy consumption from 1954 to 2015. 
Figure 3 shows the growth rate of energy consumption in China for the period 1954 to 2015. From 1954 to 1978 when the reform and opening-up policy was implemented, it fluctuated dramatically from $82.5 \%$ in 1958 to $-32.5 \%$ in 1961 . Since 1978 , the growth rate has been keeping positive, ranging from $0.2 \%$ to $16.85 \%$ except in 1981 . Apparently, the growth rate of China's energy consumption fluctuates year after year. As shown in Figure 3, intuitively it may be affected by the Five-Year Plans, since it presents a regular oscillation pattern.

\section{Empirical Results}

\subsection{EEMD Results}

Figure 2 shows that the growth rate of energy consumption fluctuates over time. Hence, we will conduct the EEMD method to unravel the dynamic or periodic characteristics of the growth rate of energy consumption on multi-timescales. The EEMD method is suitable for decomposing the growth rate of energy consumption $(E C)$ in an effort to find out the intrinsic characteristics on multiple timescales.

We set the ensemble number as 100 as suggested by Bai et al. [38] and Xu et al. [39]. The added white noise has an amplitude, specifically 0.2 times SD of the corresponding data. The decomposition of the EC variable by using the EEMD method leads to four IMF components and a trend component. They are shown in Figure 4.
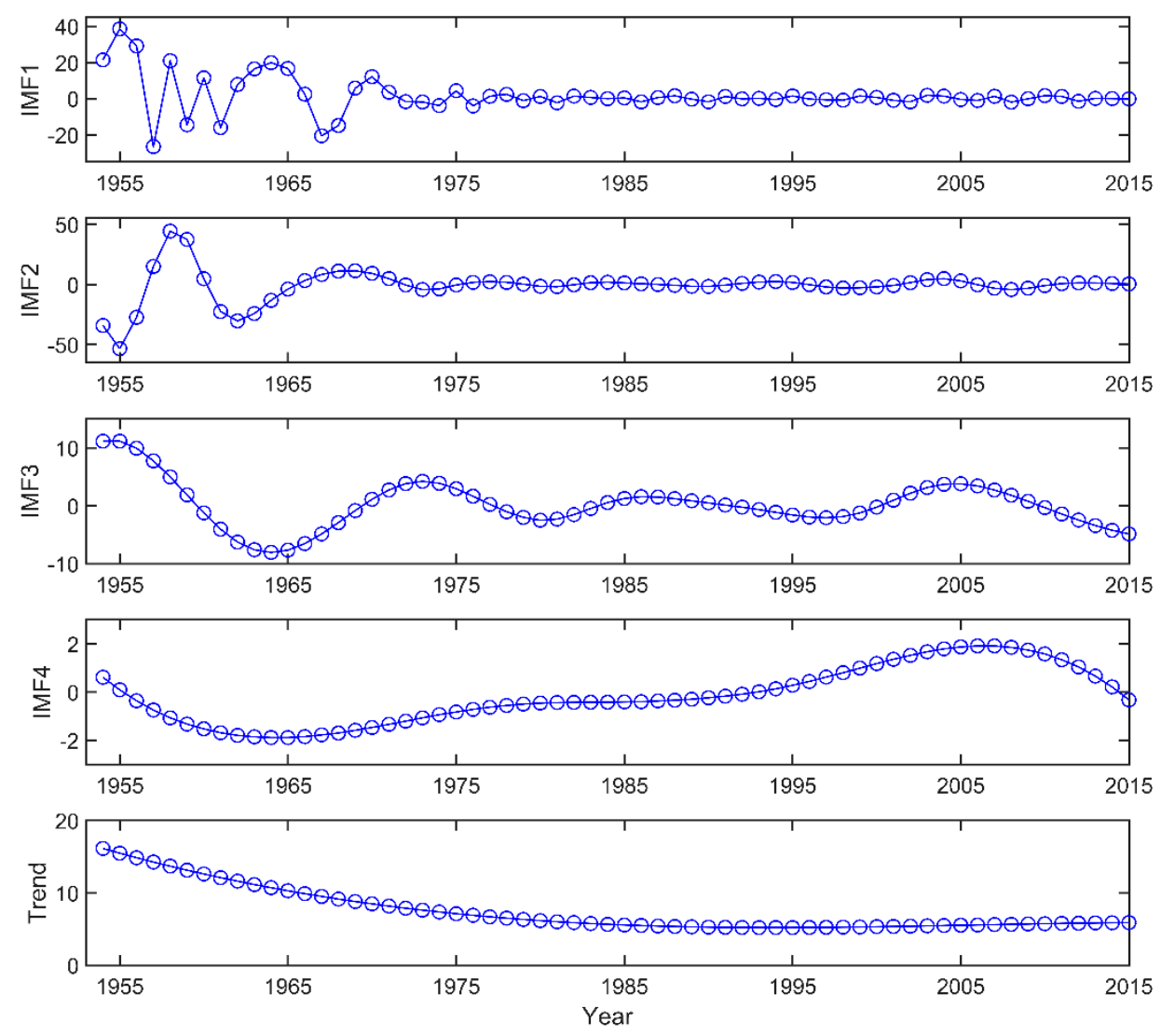

Figure 4. Intrinsic mode function (IMF) components of growth rates of energy consumption.

Figure 4 shows each IMF component. Each of them has its own physical meaning. In other words, IMF1 to IMF4 components reflect the fluctuation characteristics in descending order, specifically from high to low frequency on different timescales. Specifically, IMF1 presents the highest-frequency oscillation and IMF4 the lowest-frequency oscillation. In addition, the residua series presents a U-shaped curve that indicates the overall trend of growth rates of energy consumption in China from 
1954 to 2015. Specifically, it first decreases over time, reaches the nadir in 1993, and then increases over time. In other words, the year 1993 is the turning point. Additionally, the period and variance of each IMF component are summarized in Table 1.

Table 1. Periods and variances of IMF components for EC.

\begin{tabular}{|c|c|c|c|c|}
\hline & Significance & Period & Variance & Pearson Coefficient \\
\hline IMF1 & 90-95\% & 2.905 & 31.875 & $0.390^{* * *}$ \\
\hline IMF2 & $95 \%$ above & 7.625 & 59.532 & $0.530^{* * *}$ \\
\hline IMF3 & $50-80 \%$ & 12.200 & 5.019 & $0.442^{* * *}$ \\
\hline IMF4 & $50-80 \%$ & 53.673 & 0.414 & -0.004 \\
\hline Trend & & & 3.160 & $0.302^{* *}$ \\
\hline Total & & & 100 & \\
\hline
\end{tabular}

As shown in Figure 4 and Table 1, IMF1 and IMF2 are of high-frequency oscillation and have shorter periods (namely, IMF1 and IMF2 components with mean periods of about 3 years and 7.6 years, respectively) than low-frequency IMF3 and IMF4 (IMF3 and IMF4 components with mean periods of 12.2 and 53.7 years). Each IMF component clearly presents not only regular variation characteristics on different timescales under external forces but also the non-linear feedback of the energy-economy system.

Besides, these IMF components present not only periodic fluctuations, but also different variances. As shown in Table 1, the variance of each IMF component for the growth rate of energy consumption is presented. It can be found that IMF1 and IMF2 components combined, accounting for $90 \%$, have greater contributions than IMF3 and IMF4 components. In other words, there is little actual physical information embodied in IMF3 and IMF4 components. We place emphasis on IMF2 with about a 7.5-year period, since it accounts for about $60 \%$ of the growth rate variance. As shown in Table 1 , IMF2 has the highest Pearson correlation coefficient (0.530) with the original series data. Coincidentally, it corresponds to 1.5 times the length of the Five-Year Plan (five years) in China. In other words, the growth rate in a period of a Five-Year Plan may be not only be attributed to last year, but also will last until next year. To conclude, the Five-Year Plan policy may be the major influencing factor affecting China's energy consumption.

Of greater interest is the overall trend. A turning point occurred in 1993. Coincidentally, in 1992 China's energy consumption outpaced domestic energy production, with a deficiency of 19.14 million tons standard coal equivalent (SCE). As shown in Figure 5, the energy deficit has been widening rapidly since 1993. Since then, China has been increasingly dependent on imports of energy, for example oil. In other words, using the EEMD method, we find that the growth rate of China's energy consumption has been continuously increasing since 1993.

It is of great interest to us to examine if there exists Granger causality relationships between GDP and energy consumption. However, the relationship on multiple timescales has received little attention so far. Hence, in this study we attempt to fill this gap.

Before decomposing the growth rate of economic growth (GDP), we compare the growth rates of energy consumption and GDP. As shown in Figure 6, before 1978 when China's reform and opening-up policy was implemented, the growth rate of energy consumption outpaced the growth rate of GDP. After 1978, this development pattern reversed. From the above analysis, it follows that the policy contributed to China's economic growth. The faster economic growth implies ever-decreasing energy intensity (energy intensity is defined as energy used to generate a unit of economic output) after 1978. However, it still lags behind that of advanced industrialized countries such as, Japan, Germany and the U.S. 


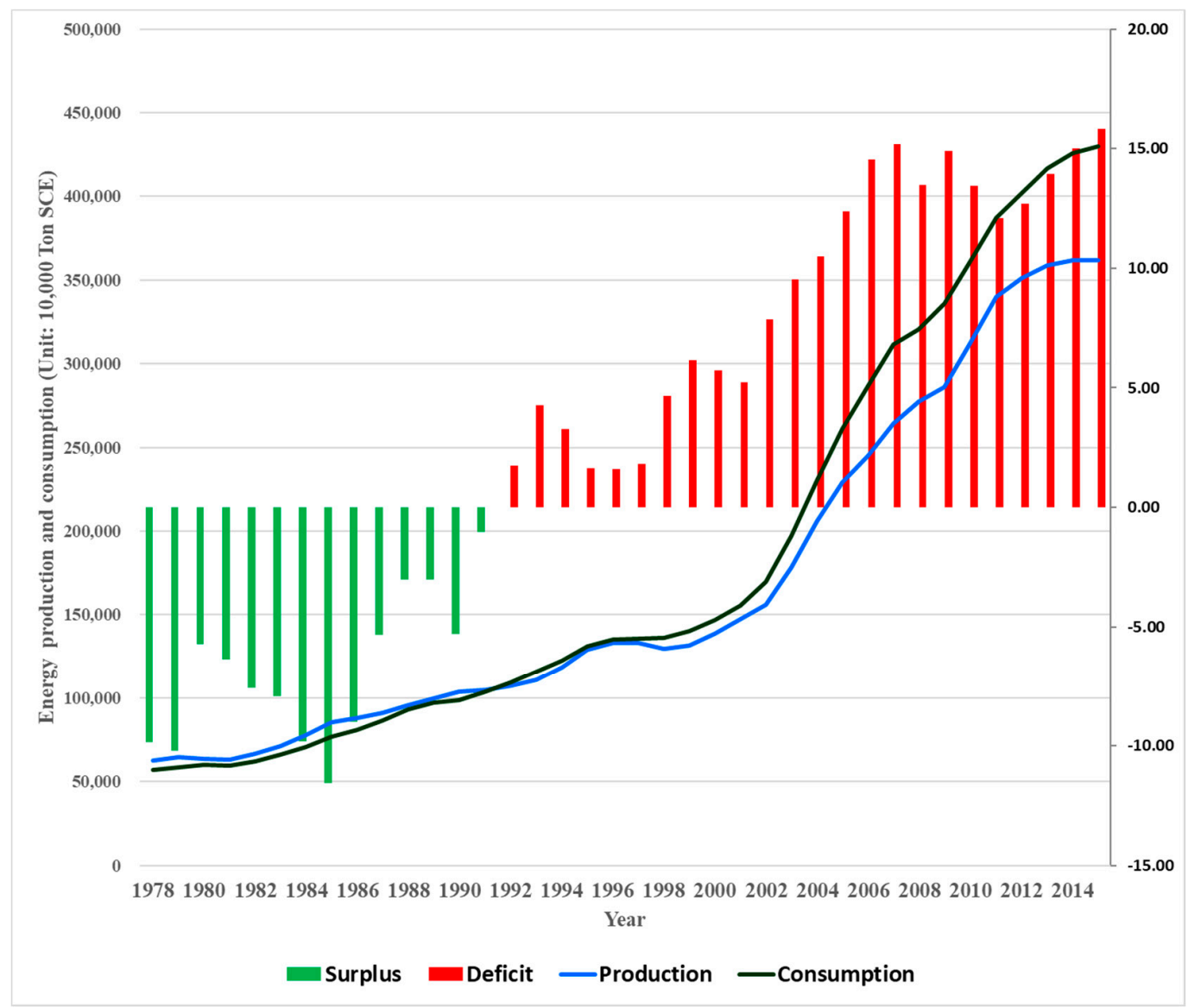

Figure 5. Energy production, consumption and deficit percentage in China, 1978-2015.

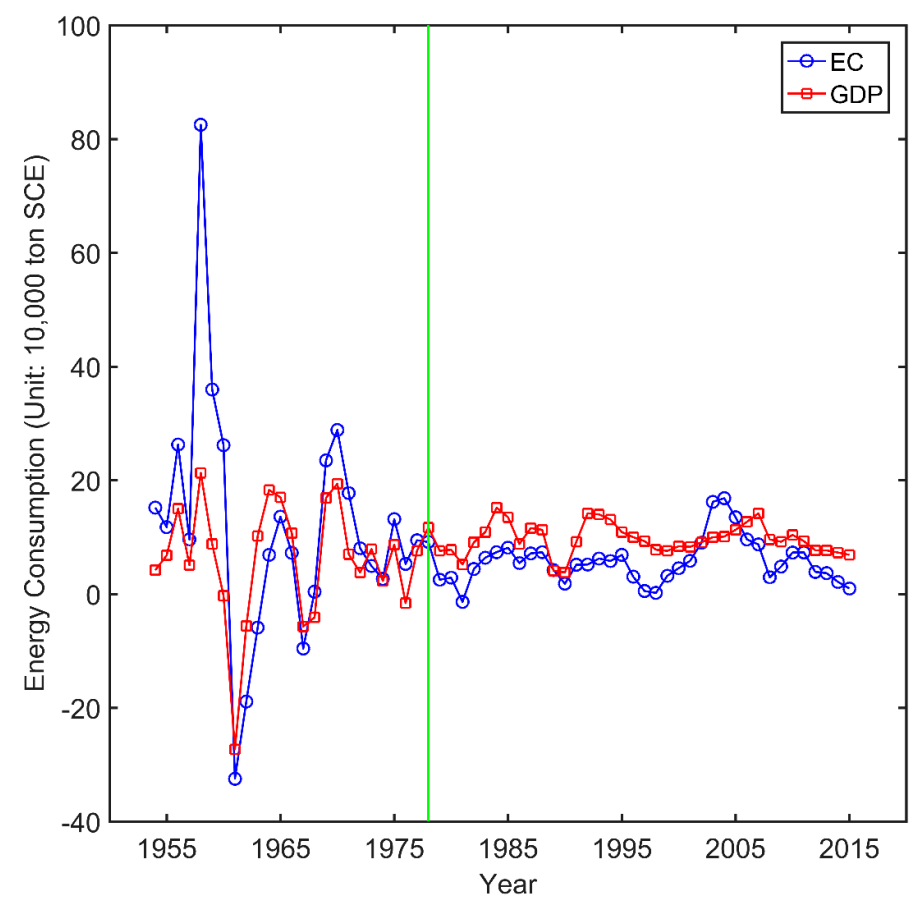

Figure 6. Growth rates of energy consumption and GDP from 1953 to 2015. 
Next, we repeated the EEMD procedure for the growth rate of GDP. Consequently, four IMF components and a trend were also obtained. For simplicity, we define the five components as IMF1_GDP, IMF2_GDP, IMF3_GDP, IMF4_GDP and Trend_GDP. For the purpose of comparison, they are plotted in Figure 7.

As shown in the first subfigure of Figure 7, IMF1_GDP presents a similar pattern with IMF1_EC, particularly after 1957. Similarly, as shown in the second subfigure, IMF2_GDP has the similar fluctuation pattern. Regarding IMF3 and 4, they have different fluctuations. Finally, we pay considerable attention to the trend components. We find that Trend_GDP has a completely different development curve from Trend_EC. In other words, the growth rate of GDP first increases and then declines gradually. In particular, Trend_GDP outpaced Trend_EC in 1976, close to the year of 1978 when the reform was implemented. To sum up, we find that the four IMF GDP components have very similar oscillations and corresponding periods with IMF components for EC.
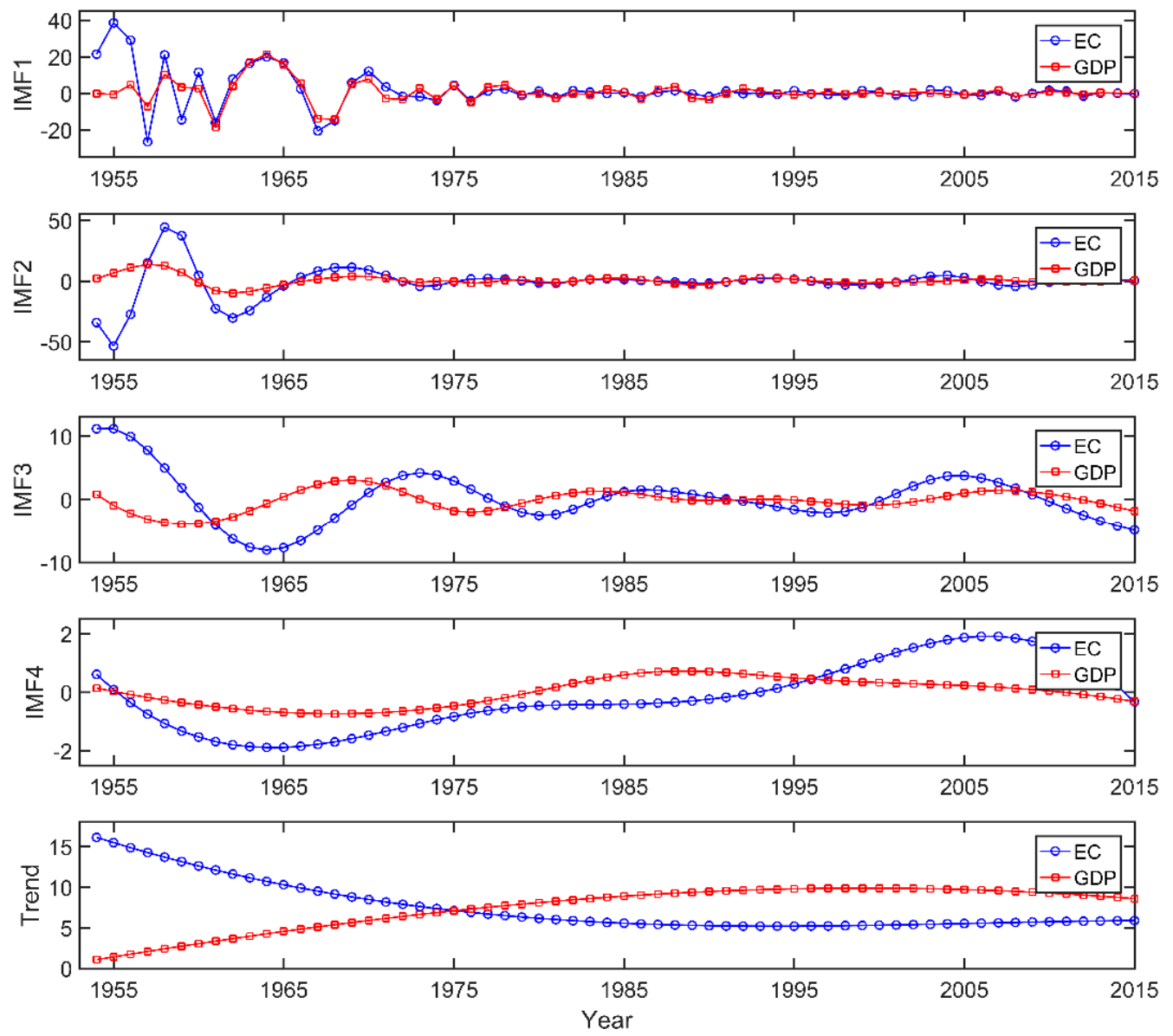

Figure 7. IMF components of growth rates of GDP and energy consumption.

\subsection{Unit Root Test Results}

Before moving to the Granger causality test, we performed the augmented Dickey Fuller unit root test (ADF test) for IMF1_GDP, IMF2_GDP, IMF3_GDP, IMF4_GDP, IMF1_EC, IMF2_EC, IMF3_EC and IMF4_EC time series, respectively, in order to verify if they were stationary.

Figure 7 shows that each IMF component seems to fluctuate up and down around zero during the sample period. Hence, no intercept and no trend are considered when testing for unit roots. The ADF test results are shown in Table 2.

As shown in Table 2, $t$ statistics for $\theta$ are reported, followed by the critical values for the $t$ test at the $1 \%, 5 \%$ and $10 \%$ significance level. From the second to fifth row, $t$ statistics for all IMF components 
for energy consumption are less than the critical values at the $10 \%$ significance level, indicating that the null hypothesis is strongly rejected. In other words, IMF1 to 4 components for energy consumption are found to be stationary. Similarly, from thesixth to ninth row, all IMF components for GDP are stationary. To sum up, the ADF test results show that each IMF component time series has no unit root, or I(0).

Table 2. Augmented Dickey-Fuller (ADF) unit root test results.

\begin{tabular}{ccccccc}
\hline $\boldsymbol{t}$ Test & $\boldsymbol{t}$-Statistic & $\boldsymbol{p}$-Value & $\mathbf{1 \%}$ Level & $\mathbf{5 \%}$ Level & $\mathbf{1 0 \%}$ Level & Lag Length \\
\hline IMF1_EC & -6.12 & 0.000 & -2.604 & -1.946 & -1.613 & 1 \\
IMF2_EC & -5.035 & 0.000 & -2.605 & -1.947 & -1.613 & 3 \\
IMF3_EC & -2.517 & 0.013 & -2.606 & -1.947 & -1.613 & 4 \\
IMF4_EC & -1.929 & 0.052 & -2.608 & -1.947 & -1.613 & 7 \\
IMF1_GDP & -6.072 & 0.000 & -2.604 & -1.946 & -1.613 & 1 \\
IMF2_GDP & -9.488 & 0.000 & -2.605 & -1.947 & -1.613 & 3 \\
IMF3_GDP & -4.838 & 0.000 & -2.605 & -1.947 & -1.613 & 3 \\
IMF4_GDP & -2.266 & 0.024 & -2.608 & -1.947 & -1.613 & 7 \\
\hline
\end{tabular}

Note: $t$-statistics in the table.

\subsection{Granger Causality Test Results}

Finally, we conducted the Granger causality test for IMF1_EC and IMF1_GDP, IMF2_EC and IMF2_GDP, IMF3_EC and IMF3_GDP, IMF4_EC and IMF4_GDP, and Trend_EC and Trend_GDP in pairs, respectively. Since causality test results are very sensitive to the length of lags, the appropriate lags can be determined by using some criterion, for example, the Akaike information criterion (AIC), Schwartz criterion (SC), etc. Hence, in this study the AIC statistic is adopted to select the length of lags. More specifically, the smaller the AIC statistic is, the better it is fitted. These Granger causality test results are summarized in Table 3.

Table 3. The Granger causality test results.

\begin{tabular}{ccccc}
\hline Null Hypothesis & Lags & F-Statistic & Probability & Decision \\
\hline IMF1_GDP does not Granger cause IMF1_EC & 4 & 12.690 & 0.000 & Reject \\
IMF1_EC does not Granger cause IMF1_GDP & 4 & 6.530 & 0.000 & Reject \\
IMF2_GDP does not Granger cause IMF2_EC & 4 & 9.333 & 0.000 & Reject \\
IMF2_EC does not Granger cause IMF2_GDP & 4 & 3.775 & 0.009 & Reject \\
IMF3_GDP does not Granger cause IMF3_EC & 4 & 2.836 & 0.034 & Reject \\
IMF3_EC does not Granger cause IMF3_GDP & 4 & 1.529 & 0.209 & Accept \\
IMF4_GDP does not Granger cause IMF4_EC & 6 & 10.489 & 0.000 & Reject \\
IMF4_EC does not Granger cause IMF4_GDP & 6 & 2.131 & 0.069 & Accept \\
Trend_GDP does not Granger cause Trend_EC & 5 & 13.486 & 0.000 & Reject \\
Trend_EC does not Granger cause Trend_GDP & 5 & 0.327 & 0.894 & Accept \\
\hline
\end{tabular}

In the context of IMF1, it can be found that there exists a bidirectional Granger causality relationship between GDP and EC. Similarly, in the context of IMF2, a bidirectional Granger causality relationship is also found. Although IMF3 and IMF3 made little contribution to explaining the time series, they reflect how these time-series change in the longer run. We still provide the Granger causality test results. In the context of IMF3 and IMF4, a unidirectional relationship running from GDP to EC indicating that in the longer run the growth rate of energy consumption is driven by the growth rate of economic growth. Last but not least, we repeat the ADF unit root test for Trend_EC and Trend_GDP time series to investigate if they are stationary. The results show that they have no unit roots. Subsequently, we performed the Granger causality test. As shown in Table 3, there is a unidirectional causality relationship running from GDP to EC in the long run. 
To sum up, there exists a short-run bidirectional Granger causality relationship between economic growth and energy consumption and a long-run unidirectional causality relationship running from economic growth to energy consumption. This reason may lie in two aspects. In the short run, China's economy grows rapidly depending on the large scale of the development of industry, which leads to more energy being used. In the reverse direction, a great deal of energy consumption sustains the rapid development of industry, which in turn contributes to China's rapid economic growth. Hence, industry plays a substantial and mediating role in the energy-economy system. In the long run, economic growth is the solo driving factor of energy consumption. On the one hand, China's rapid and continuous economy growth stimulates energy production and energy consumption. In particular energy consumption signals if the economy increases and declines. If the growth rate of GDP declines, demand for energy also decreases, and energy production in turn shrinks. On the other hand, as the economy grows, income levels and living standards increase. A large number of energy-intensive products and services like cars, air-conditioners, and central heating systems etc. are consumed, which causes higher energy consumption. In other words, a large amount of energy cannot be consumed without continuous and rapid economic growth.

Moreover, there may be an extended explanation of the relationship between energy consumption and economic growth. This causality relationship discloses the nexus of energy matters and the economy. Sufficient energy supply is imperative for sustainable economic development since energy powers industrial systems. Moreover, various goods, for example, private cars, and services, for example, central heating systems, are also highly dependent on energy as income levels increase. To sum up, energy is of vital importance not only for production but also for consumption in the economy. On the other hand, a highly energy-dependent economy may cause environmental degradation that will affect sustainable development. Hence, for sustainable economic development an appropriate and harmonious relationship between energy consumption and economy is required.

\section{Conclusions}

In this paper, we revisited the Granger causality relationship between economic growth and energy consumption in China from a multi-timescale perspective. In the first stage we analyzed the characteristics of the annual growth rate of China's energy consumption from 1954 to 2015 by means of the EEMD method. Four intrinsic mode function components with different periods on different timescales and an overall trend component were obtained from the decomposition method. An important finding from the overall trend component is that the year 1993 was the turning point for energy consumption growth, coinciding with the moment China's energy consumption outpaced its energy production. Furthermore, China's energy consumption gradually grew after 1993 and will keep increasing in the future. Then, we repeated the same procedures for the growth rate of China's economic growth. Similarly, four IMF components and an overall trend were also obtained. In the second stage we performed the Granger causality test on different timescales. The results showed that there exists a short-run causality relationship running from GDP to energy consumption, and vice versa, and a long-run unidirectional causality relationship running from GDP to energy consumption.

These conclusions enable us to obtain a series of economic, social, and ecological implications. Firstly, energy must be the first priority in China's economic growth since its economy heavily depends on energy sources. Since 1992, China's energy consumption has outpaced its production, turning China into one the largest energy importers, especially of oil. Energy shortages seriously affect China's sustainable development. To address the problem, China has expanded sources of energy imports. On the other hand, China's central government has made great efforts to improve energy efficiency in a bid to balance the relationship between rapid economic growth and the potentially huge energy gap. Hence, a harmonious relationship between energy consumption and the economy is urgently required. Secondly, Chinese society is also heavily dependent on energy use. As income levels increase, a massive number of energy-intensive products and services, for example, private vehicles and central heating, are in demand in China leading to the consumption of a great deal of energy. To sustain 
better living standards, energy is one of the most indispensable prerequisites. Finally, since China has been experiencing rapid economic growth various pollutants caused by high energy consumption have led to serious environmental deterioration and even ecological disasters. For instance, a large scale of haze and fog events caused by coal combustion frequently occur in most areas of China. Moreover, China is also facing major challenges of water and soil pollution. Overdependence on energy consumption for the Chinese economy has posed a great threat to the country's sustainable development and ecological environment. Hence, improvements in energy efficiency, the reduction of energy use and the pollutants this causes are urgently needed in order to develop an environmentally friendly society and sustainable development.

Acknowledgments: The authors are grateful for the financial support provided by the National Natural Science Foundation of China (71742001, 41761021), the Humanities and Social Science Research Program of the Ministry of Education of China (17YJC790061), and the China Postdoctoral Science Foundation (2017M621740).

Author Contributions: Lei Jiang proposed the idea of this article and designed this study. Ling Bai analyzed the data. Besides, Lei Jiang wrote and revised the manuscript. All authors read and approved the manuscript.

Conflicts of Interest: The authors declare no conflicts of interest.

\section{References}

1. Jiang, L.; Folmer, H.; Ji, M. The drivers of energy intensity in China: A spatial panel data approach. China Econ. Rev. 2014, 31, 351-360. [CrossRef]

2. British Petroleum. Statistical Review of World Energy. 2016. Available online: https://www.bp.com/content/ dam/bp/pdf/energy-economics/statistical-review-2016/bp-statistical-review-of-world-energy-2016-fullreport.pdf (accessed on 30 June 2016).

3. Jiang, L.; Folmer, H.; Ji, M.; Tang, J. Energy efficiency in the Chinese provinces: A fixed effects stochastic frontier spatial Durbin error panel analysis. Ann. Reg. Sci. 2017, 58, 301-319. [CrossRef]

4. Zhang, H.; Lahr, M.L. China's energy consumption change from 1987 to 2007: A multiregional structural decomposition analysis. Energy Policy 2014, 67, 682-693. [CrossRef]

5. Song, M.; Wang, S.; Yu, H.; Yang, L.; Wu, J. To reduce energy consumption and to maintain rapid economic growth: Analysis of the condition in China based on expended IPAT model. Renew. Sustain. Energy Rev. 2011, 15, 5129-5134. [CrossRef]

6. Crompton, P.; Wu, Y. Energy consumption in China: Past trends and future directions. Energy Econ. 2004, 27, 195-208. [CrossRef]

7. Liu, Y. Exploring the relationship between urbanization and energy consumption in China using ARDL (autoregressive distributed lag) and FDM (factor decomposition model). Energy 2009, 34, 1846-1854. [CrossRef]

8. Cattaneo, C.; Manera, M.; Scarpa, E. Industrial coal demand in China: A provincial analysis. Resour Energy Econ. 2008, 33, 12-35. [CrossRef]

9. Jiang, Z.; Lin, B. China's energy demand and its characteristics in the industrialization and urbanization process. Energy Policy 2012, 49, 608-615. [CrossRef]

10. Fu, F.; Liu, H.; Polenske, K.R.; Li, Z. Measuring the energy consumption of China's domestic investment from 1992 to 2007. Appl. Energy 2013, 102, 1267-1274. [CrossRef]

11. Li, F.; Song, Z.; Liu, W. China's energy consumption under the global economic crisis: Decomposition and sectoral analysis. Energy Policy 2014, 64, 193-202. [CrossRef]

12. Lin, B.; Ouyang, X. Energy demand in China: Comparison of characteristics between the US and China in rapid urbanization stage. Energy Convers. Manag. 2014, 79, 128-139. [CrossRef]

13. Wang, Q. Effects of urbanisation on energy consumption in China. Energy Policy. 2014, 65, 332-339. [CrossRef]

14. Huang, N.E.; Shen, Z.; Long, S.R.; Wu, M.C.; Shih, H.H.; Zheng, Q.; Yen, N.C.; Tung, C.C.; Liu, H.H. The empirical mode decomposition and the Hilbert spectrum for nonlinear and non-stationary time series analysis. Proc. R. Soc. A Math. Phys. Eng. Sci. 1998, 454, 903-995. [CrossRef]

15. Yu, L.; Wang, S.; Lai, K.K. Forecasting crude oil price with an EMD-based neural network ensemble learning paradigm. Energy Econ. 2008, 30, 2623-2635. [CrossRef] 
16. Zhang, X.; Yu, L.; Wang, S.; Lai, K.K. Estimating the impact of extreme events on crude oil price: An EMD-based event analysis method. Energy Econ. 2009, 31, 768-778. [CrossRef]

17. Xiong, T.; Bao, Y.; Hu, Z. Beyond one-step-ahead forecasting: Evaluation of alternative multi-step-ahead forecasting models for crude oil prices. Energy Econ. 2013, 40, 405-415. [CrossRef]

18. Yu, L.; Li, J.; Tang, L.; Wang, S. Linear and nonlinear Granger causality investigation between carbon market and crude oil market: A multi-scale approach. Energy Econ. 2015, 51, 300-311. [CrossRef]

19. Yu, L.; Wang, Z.; Tang, L. A decomposition-ensemble model with data-characteristic-driven reconstruction for crude oil price forecasting. Appl. Energy 2015, 156, 251-267. [CrossRef]

20. Zhang, J.L.; Zhang, Y.J.; Zhang, L. A novel hybrid method for crude oil price forecasting. Energy Econ. 2015, 49, 649-659. [CrossRef]

21. Shao, Z.; Gao, F.; Yang, S.L.; Yu, B.G. A new semiparametric and EEMD based framework for mid-term electricity demand forecasting in China: Hidden characteristic extraction and probability density prediction. Renew. Sustain. Energy Rev. 2015, 52, 876-889. [CrossRef]

22. Shao, Z.; Gao, F.; Zhang, Q.; Yang, S.L. Multivariate statistical and similarity measure based semiparametric modeling of the probability distribution: A novel approach to the case study of mid-long term electricity consumption forecasting in China. Appl. Energy 2015, 156, 502-518. [CrossRef]

23. Afanasyev, D.O.; Fedorova, E.A.; Popov, V.U. Fine structure of the price-demand relationship in the electricity market: Multi-scale correlation analysis. Energy Econ. 2015, 51, 215-226. [CrossRef]

24. Zhang, X.P.; Cheng, X.M. Energy consumption, carbon emissions, and economic growth in China. Ecol. Econ. 2009, 68, 2706-2712. [CrossRef]

25. Wang, Y.; Wang, Y.; Zhou, J.; Zhu, X.; Lu, G. Energy consumption and economic growth in China: A multivariate causality test. Energy Policy 2011, 39, 4399-4406. [CrossRef]

26. Zhang, C.; Xu, J. Retesting the causality between energy consumption and GDP in China: Evidence from sectoral and regional analyses using dynamic panel data. Energy Econ. 2012, 34, 1782-1789. [CrossRef]

27. Herrerias, M.J.; Joyeux, R.; Girardin, E. Short-and long-run causality between energy consumption and economic growth: Evidence across regions in China. Appl. Energy 2013, 112, 1483-1492. [CrossRef]

28. Bozoklu, S.; Yilanci, V. Energy consumption and economic growth for selected OECD countries: Further evidence from the granger causality test in the frequency domain. Energy Policy 2013, 63, 877-881. [CrossRef]

29. Mutascu, M. A bootstrap panel Granger causality analysis of energy consumption and economic growth in the G7 countries. Renew. Sustain. Energy Rev. 2016, 63, 166-171. [CrossRef]

30. Talebi, M.; Alvandizade, A.; Roshanroo, M. Granger causality relationship between energy consumption and economic growth in Iran (1980-2009). Interdiscip. J. Contemp. Res. Bus. 2012, 4, 559.

31. Wolde-Rufael, Y. Electricity consumption and economic growth in transition countries: A revisit using bootstrap panel Granger causality analysis. Energy Econ. 2014, 44, 325-330. [CrossRef]

32. Sari, R.; Ewing, B.T.; Soytas, U. The relationship between disaggregate energy consumption and industrial production in the United States: An ARDL approach. Energy Econ. 2008, 30, 2302-2313. [CrossRef]

33. Soytas, U.; Sari, R. The relationship between energy and production: Evidence from Turkish manufacturing industry. Energy Econ. 2007, 29, 1151-1165. [CrossRef]

34. Bruns, G.; Stern, D. Is there really granger causality between energy use and output? Energy J. 2014, 35, 101-134. [CrossRef]

35. Dergiades, T.; Tsoulfidis, L. Estimating residential demand for electricity in the United States, 1965-2006. Energy Econ. 2008, 30, 2722-2730. [CrossRef]

36. Liddle, B.; Lung, S. Revisiting energy consumption and GDP causality: Importance of a priori hypothesis testing, disaggregated data, and heterogeneous panels. Appl. Energy 2015, 142, 44-55. [CrossRef]

37. Huang, N.E.; Shen, Z.; Long, S.R. A new view of nonlinear water waves: The Hilbert spectrum. Annu. Rev. Fluid Mech. 1999, 31, 417-457. [CrossRef]

38. Bai, L.; Xu, J.; Chen, Z.; Li, W.; Liu, Z.; Wang, Z. The regional features of temperature variation trends over Xinxiang in China by the ensemble empirical mode decomposition method. Int. J. Climatol. 2014, 35, 3229-3237. [CrossRef]

39. Xu, J.; Chen, Y.; Bai, L.; Xu, Y. A hybrid model to simulate the annual runoff of the Kaidu River in northwest China. Hydrol. Earth Syst. Sci. Discuss. 2016, 20, 1-33.

40. Wu, Z.; Huang, N.E. Ensemble empirical mode decomposition: A noise-assisted data analysis method. Adv. Adapt. Data Anal. 2009, 1, 1-41. [CrossRef] 
41. Wu, Z.; Huang, N.E.; Long, S.R.; Peng, C.K. On the trend, detrending, and variability of nonlinear and nonstationary time series. Proc. Natl. Acad. Sci. USA 2007, 104, 14889-14894. [CrossRef] [PubMed]

42. Wu, Z.; Huang, N.E.; Wallace, J.M.; Smoliak, B.V.; Chen, X. On the time-varying trend in global-mean surface temperature. Clim. Dyn. 2011, 37, 759-773. [CrossRef]

43. Dickey, D.A.; Fuller, W.A. Distribution of the estimators for autoregressive time series with a unit root. J. Am. Stat. Assoc. 1979, 74, 427-431.

44. Dickey, D.A.; Fuller, W.A. Likelihood ratio statistics for autoregressive time series with a unit root. Econometrica 1981, 49, 1057-1072. [CrossRef]

45. Granger, C.W. Investigating causal relations by econometric models and cross-spectral methods. Econometrica 1969, 37, 424-438. [CrossRef]

(C) 2017 by the authors. Licensee MDPI, Basel, Switzerland. This article is an open access article distributed under the terms and conditions of the Creative Commons Attribution (CC BY) license (http:/ / creativecommons.org/licenses/by/4.0/). 